\title{
Rising to the Challenge
}

\author{
Marvin L. Birnbaum, MD, PhD
}

\section{Now's the day and now's the hour.}

Burns, Bannockburn

Much has happened since I last addressed the issues associated with the development of the science of prehospital, emergency, and disaster medicine. The need for a coordinating, overseeing, and standard-setting organization to guide the development of this science has been noted repeatedly in most of the international forums in which I have had the privilege of participating. Furthermore, the World Association for Disaster and Emergency Medicine (WADEM) has been singled out as best suited to meet the challenges tendered by these forums.

It has been assumed that WADEM can meet the challenges directed to it. I believe the reasons for the selection of the WADEM for these missions has been its growth, its international representation, and that WADEM and its activities have been spreading rapidly across the medical world. This is evidenced by the observations that WADEM membership now includes people from 60 countries. Furthermore, in the last month, persons from 87 countries have accessed Prehospital and Disaster Medicine via the Internet. Persons from more that 45 countries attended the 13th World Congress in Lyon in May of this year. Thus, it seems clear that an expectation exists that WADEM will fulfill these charges.

In light of these challenges, the WADEM, much like any disaster and emergency manager, recognized the need to clearly define its purpose (why it exists), and its mission (what are its responsibilities) in order to better identify needs and to seek the proper resources to satisfy those needs. The WADEM began reevaluating its mission, purpose, and structure at the 5th APCDM in Vancouver in the fall of 2000. After several months of discussion, a new Statement of Purpose emerged and was approved by the WADEM General Assembly in Lyon. It reads as follows:

Underscoring a commitment to advance the frontier of disaster and emergency research, The World Association for Disaster and Emergency Medicine (WADEM) was created, originally as the Club of Mainz in 1976, to focus its members' expertise on the scientific investigation and improvement of disaster and emergency response. Our membership is open to physicians, nurses, administrators, behavioral scientists, emergency medical technicians and paramedics, public health, and other relevant experts in the field from all continents and cultures. Ultimately, the organization exists to foster international collaboration in the application of knowledge gained from data collected through qualitative and quantitative research to the development of strategies aimed at promoting all aspects of human health, decreasing susceptibility, and increasing resilience to future health disasters and emergencies. To this end, WADEM publishes its own international, peerreviewed journal, Prehospital and Disaster Medicine, sponsors biennial World Congresses, and supports regional conferences of its affiliated member societies.

Further discussions explored how best to accomplish this purpose. The Board searched for ways that would uniquely serve the prehospital and disaster community, a group within which "operational" organizations (i.e. field operations dedicated to disaster and emergency response) were well-represented. The WADEM found that its membership had a unique ability to provide leadership in the areas of disaster research, education, assessment, standardsetting, and international collaboration: The WADEM would best serve the disaster community as a nonoperational (i.e. non-field operations) organization, thus remaining neutral among operational groups. The General Assembly, again in Lyon, approved the new Mission Statement as conceived from these discussions:

The World Association for Disaster and Emergency Medicine is an international, humanitarian association dedicated to the improvement of disaster and emergency medicine. Fostering international collaboration, the organization is inclusive, culturally sensitive, unbiased, ethical and dynamic in its approach. While individual members are active in field operations, the organization remains nonoperational, fulfilling its mission through:

1. Facilitation of academic and research-based education and training

2. Interpretation and exchange of information through its global network of members and publications

3. Development and maintenance of evidencebased standards of emergency and disaster health care and provision of leadership concerning their integration into practice

4. Coordination of data collection and provision of 
direction in the development of standardized disaster assessment and research and evaluation methodologies

5. Encouraging publication and presentation of evidence-based research findings and scientific publication and international conferences and congresses

The WADEM simultaneously reevaluated its organizational structure to determine if it would support its expansion and allow the realization of these goals. Substantial work had begun by the late Mike Moles and Demetrios Pyrros relative to the restructuring of WADEM to include a House of Delegates that would bring into the WADEM the views, needs, and operations of other organizations, and thus, would contribute to the selection of projects and priorities of WADEM. This restructuring of WADEM was also approved by the General Assembly of WADEM in Lyon.

As a result, WADEM now has a more clearly defined role in the evolution of the science of prehospital and disaster medicine. Its evolution will enable WADEM to meet the critical informational needs of the prehospital and disaster community and to become the coordinating, overseeing, and standard-setting organization necessary to guide the development of this science. Ultimately, it will be able to provide the assessment, education, research, and standards necessary to improve emergency and disaster response worldwide.

However, the scope of our mission is daunting as the following examples will demonstrate:

1. At the 5th Asia-Pacific Conference on Disaster Medicine, WADEM was asked to continue the development of the White Papers on disaster management, health and public health, education and training, research, psychosocial aspects, and plans; task forces on terrorism, land mines, and emerging infections; standardized evaluation tools; a disaster medicine resource list; a standardized template for the assessment of medical needs; a standardized curriculum for disaster medicine/management; and an information and data clearinghouse. The Conference also charged WADEM with the provision of future courses on applied disaster research.

2. The World Health Organization (WHO) suggested that WADEM provide consultation to $\mathrm{WHO}$ as needed, facilitate access to educational programs, link relevant websites, produce a glossary of terminology, standardize curricula, coordinate training activities, develop an inventory of indicators, and assist with the development of a standardized set of applied tools for data collection in the field. Importantly, WHO also suggested that WADEM seek input from other related organizations.
3. In addition, in a recent review of research in disaster medicine (in which PDM served as a primary resource), the Active Learning Network for Accountability and Performance in Humanitarian Assistance (ALNAP) (an interagency forum working to improve learning and accountability in the international humanitarian system) suggested the following: "Strong consideration should be given to following and supporting the Utstein Templates model in developing the discourse around disaster medicine research as the current best possibility for generating a unified language and common data sets for the field. An Internet-based Delphi study on the priority topics for Disaster Medicine research, along the lines of that sponsored by the Association of American Medical Colleges on the future of medical practice and medical education, should be considered as a way of generating systematic data on research priorities. This study should be undertaken in conjunction with the World Association for Disaster and Emergency Medicine (WADEM) and other associated groups." ${ }^{1}$ The ALNAP also provided several recommendations relative to the organization of Disaster Medicine research that included: "Consideration should be given to the development of a Cochrane collaboration-like structure for advancing the aggregation of research into disaster medicine. Consideration should be given to establishing a permanent or semi-permanent secretariat along the lines of the KAMEDO Project to stimulate, initiate, coordinate and communicate on activities in disaster medicine research in Australia and internationally." 1

This partial list of tasks is long and comprehensive, and only addresses the disaster portion of the discipline. Clearly, WADEM has stepped up to the plate of challenges directed its way. However, given these tasks, it is vital to the success of these ventures to identify the resources to accomplish this long list of charges. Its ability to do so depends on all of us who are a part of this profession. Without the ACTIVE participation of each of you, accomplishing these tasks will be impossible. The work will be done by task forces and committees, and each of you must volunteer your expertise and time where they mesh best with the work that remains to be done. Some of you will need to help identify and procure the necessary resources. Others will need to make things happen. Success in the ability to meet these needs depends on you and not on just a few dedicated people.

Now is the time to really show your stuff, and for us to work together to meet this noble mission. The needs are great and we need your help to identify the resources with which to address these needs. The WADEM has risen to the challenge; will you?

We must take the current when it serves, Or lose our ventures.

Shakespeare, Julius Caesar, Act 4, Scene 3

\section{References}

1. The Active Learning Network for Accountability and Performance in Humanitarian Assistance (ALNAP): Research in Disaster Medicine: Executive Summary. ALNAP: London, 2001. 